\title{
The impact of delivery risk on optimal production and futures hedging*
}

\author{
Axel F. A. Adam-Müller \\ Center of Finance and Econometrics \\ Department of Economics \\ University of Konstanz, D - 78457 Konstanz, Germany \\ Tel.: +49-7531-882346, Fax: +49-7531-883559 \\ email: axel.adam-mueller@uni-konstanz.de \\ Kit Pong Wong \\ School of Economics and Finance \\ University of Hong Kong, Pokfulam Road, Hong Kong \\ Tel.: +852-2859-1044, Fax: +852-2548-1152 \\ email: kpwong@econ.hku.hk
}

March 15, 2002

\begin{abstract}
Multiple delivery specifications exist on nearly all commodity futures contracts. Sellers are typically allowed to choose among several grades of the underlying commodity. On the delivery day, the futures price converges to the spot price of the cheapest-to-deliver grade rather than to that of the par-delivery grade of the commodity. This imposes an additional delivery risk on hedgers. This paper derives the optimal production and futures hedging strategy for a risk-averse competitive firm in the presence of delivery risk. We show that, depending on its relative valuation, the delivery option may induce the firm to produce more than in the absence of delivery risk. If delivery risk is additively related to commodity price risk, the firm will under-hedge its exposure to commodity price risk. If delivery risk is multiplicatively related to commodity price risk, the firm will under- or over-hedge this exposure. For constant relative risk aversion, this is illustrated by a numerical example.
\end{abstract}

JEL classification: G11, D81

Keywords: delivery risk, futures, risk management, production

${ }^{*}$ We gratefully acknowledge financial support from the Germany/Hong Kong Joint Research Scheme provided by the German Academic Exchange Service (DAAD) and the Hong Kong Research Grants Council (RGC). We would like to thank Günter Franke and Donald Lien for very helpful comments and Harald Lohre for valuable research assistance. Remaining errors are our responsibility. 


\title{
The impact of delivery risk on optimal production and futures hedging
}

\begin{abstract}
Multiple delivery specifications exist on nearly all commodity futures contracts. Sellers are typically allowed to choose among several grades of the underlying commodity. On the delivery day, the futures price converges to the spot price of the cheapest-to-deliver grade rather than to that of the pardelivery grade of the commodity. This imposes an additional delivery risk on hedgers. This paper derives the optimal production and futures hedging strategy for a risk-averse competitive firm in the presence of delivery risk. We show that, depending on its relative valuation, the delivery option may induce the firm to produce more than in the absence of delivery risk. If delivery risk is additively related to commodity price risk, the firm will under-hedge its exposure to commodity price risk. If delivery risk is multiplicatively related to commodity price risk, the firm will under- or over-hedge this exposure. For constant relative risk aversion, this is illustrated by a numerical example.
\end{abstract}

JEL classification: D81; G11

Keywords: delivery risk, futures, risk management, production

\section{Introduction}

Many commodity futures contracts possess options as to what, where, when and how much of the underlying the seller of the futures contract can deliver. These multiple delivery specifications are known as the quality option, the location option, the timing option and the quantity option. They are embedded in futures contracts in order to constrain the severity of market manipulation such as squeezes and corners. ${ }^{1}$ This paper concentrates on the optimal production and futures hedging decision of a commodity producer in the presence of a quality option. ${ }^{2}$ If the seller of

\footnotetext{
${ }^{1}$ Pirrong (1993) derives necessary and sufficient conditions for manipulating futures prices at contract expiry. Pirrong (2001) compares the probability of market manipulation for deliverysettled with that for cash-settled futures contracts.

${ }^{2}$ If a commodity at different locations is interpreted as different grades of the commodity, there is no difference between location options and quality options. For location options, see Garbade and Silber (1983a) and Pirrong, Kormendi and Meguire (1994). Financial futures contracts with delivery options are analyzed by Gay and Manaster $(1986,1991)$, Kane and Markus (1986) and Hemler (1990).
} 
the futures contract exercises the quality option by deviating from the par-delivery grade, there will usually be a correction of the futures price that the seller receives. Upward corrections are called premiums, downward correction are called discounts. However, the realized price difference between the par-delivery grade and a nonpar-delivery grade can deviate significantly from the premium or discount of this non-par-delivery grade. Therefore, the seller can minimize his cost by delivering the cheapest-to-deliver grade. ${ }^{3}$ It follows that the (corrected) futures price on the delivery day converges to the spot price of the cheapest-to-deliver grade rather than the spot price of the par-delivery grade. As shown by Kamara and Siegel (1987), Lien $(1988,1991)$ and Viswanath and Chatterjee (1992), delivery options have an impact on optimal futures positions provided that a significant proportion of open interest in a futures contract is physically delivered. ${ }^{4} 5$

In particular, hedgers are exposed to an additional delivery risk vis-à-vis the underlying price risk since it is uncertain which grade would be the cheapest to deliver. This delivery risk cannot be hedged such that hedging the price risk of the underlying is impaired by the delivery risk embedded in the futures contract. ${ }^{6}$ As a consequence, the regression approach to finding the variance minimizing hedge ratio is no longer appropriate as shown by Kamara and Siegel (1987). ${ }^{7}$

This paper analyzes the effect of the quality option embedded in commodity futures contracts on a producer's optimal production and futures hedging decision in a competitive environment. There are three main findings: First, delivery risk

\footnotetext{
${ }^{3}$ The cheapest-to-deliver grade is the grade with the minimum delivery-adjusted spot price among all deliverable grades.

${ }^{4}$ Peck and Williams $(1991,1992)$ provide evidence for the significance of physical delivery. They document that deliveries on the Chicago Board of Trade (CBOT) wheat, corn and soybean futures markets and the New York Commodity Exchange copper futures market are on average around $15 \%$ of the peak open interest in each delivery month in the 1970s and 1980s. On the delivery day, this figure is approximately $50 \%$.

${ }^{5}$ Lien $(1988,1991)$ analyzes the welfare effects of introducing a delivery option into an existing futures contract. Garbade and Silber (1983b) compare the welfare effects of physical delivery and cash settlement.

${ }^{6}$ This was first noted by Garbade and Silber (1983a), but does not necessarily hold if there are options on the futures contract, see Lien and Wong (2002), or dynamically complete markets.

${ }^{7}$ However, Viswanath and Chatterjee (1992) show that the difference is not economically significant for the CBOT wheat contract between 1970 and 1981. The regression approach has been proposed by Benninga, Eldor and Zilcha $(1983,1984)$, Lence (1995) and others.
} 
has a positive impact on output if the producer considers the delivery option more valuable than the market does. Second, we analyze risk management with futures contracts and show that the optimal hedge ratio is below one if the delivery risk embedded in a futures contract is independent of the level of spot prices at the delivery date. Third, if the amount of delivery risk increases with the level of spot prices, the optimal hedge ratio may also be above one despite the fact that futures hedging creates unhedgeable delivery risk.

The paper by Kamara and Siegel (1987) comes closest to ours. However, we extend their work in at least three respects: Firstly, Kamara and Siegel (1987) analyze the case of two deliverable grades with jointly normally distributed prices having equal variance whereas this paper captures the effect of any number of deliverable grades without relying on normality assumptions. Secondly, our model allows for more general preferences as compared to the mean-variance framework used by Kamara and Siegel (1987). Finally, they take the initial exposure as given and focus on optimal hedging whereas this paper endogenizes the production decision.

This paper is organized as follows: Section 2 delineates a single-period model of a risk-averse competitive firm facing both price risk and delivery risk. The impact of delivery risk on the optimal production decision is presented in Section 3. Optimal risk management with futures is analyzed in Section 4. Section 5 concludes.

\section{The model}

Consider a one-period model with two dates, indexed by $t=0$ and 1 . There is a commodity which has several grades, labeled as grades $1,2, \ldots, n$, where $n \geq 2$. At $t=0$, a risk-averse firm operating in a competitive environment produces grade 1 of the commodity according to a cost function $C(Q)$ where $Q$ is the firm's output level to be sold at $t=1 ; C(0) \geq 0, C^{\prime}(Q)>0$ and $C^{\prime \prime}(Q)>0$. When making its production decision at $t=0$, the firm neither knows the spot price of grade 1 of the commodity at $t=1$, denoted $\tilde{P}_{1}$, nor the spot prices of the other grades, denoted 
$\tilde{P}_{2}, \tilde{P}_{3}, \ldots, \tilde{P}_{n} \cdot{ }^{8}$ The support of $\tilde{P}_{i}$ is given by $\left[\underline{P_{i}}, \overline{P_{i}}\right]$ with $0<\underline{P_{i}}<\overline{P_{i}}<\infty$ for each $i$. Since $\tilde{P}_{1}$ is random, the firm is exposed to commodity price risk.

At $t=0$, the firm can trade infinitely divisible futures contracts in a competitive futures market where contracts mature at $t=1$. Let $H$ denote the number of futures contracts sold (purchased if $H$ is negative) by the firm. The futures price at $t=0$, denoted $F$, is given.

At maturity at $t=1$, sellers of the futures contracts have the right to choose among the deliverable grades $1,2, \ldots, n$ of the commodity the grade they want to deliver for the fulfillment of their obligations. ${ }^{9}$ Since sellers exercise this delivery option by choosing the cheapest-to-deliver grade, the futures price at $t=1$ is equal to the minimum of $\tilde{P}_{1}, \tilde{P}_{2}, \ldots, \tilde{P}_{n} \cdot{ }^{10}$ Thus, there is an additional delivery risk visà-vis the price risk to which the firm is exposed should it enter into a non-trivial futures position $H \neq 0$.

The firm's profits at $t=1$ are given by ${ }^{11}$

$$
\tilde{\Pi}=\tilde{P}_{1} Q-C(Q)+\left[F-\min \left(\tilde{P}_{1}, \tilde{P}_{2}, \ldots, \tilde{P}_{n}\right)\right] H
$$

The firm has a von Neumann-Morgenstern utility function $U(\Pi)$, defined over its profits at $t=1$, with $U^{\prime}(\Pi)>0$ and $U^{\prime \prime}(\Pi)<0$, indicating risk aversion. The firm's decision problem at $t=0$ is to choose an output level $Q$ and a futures position $H$ so as to maximize the expected utility of its profits at $t=1$,

$$
\max _{Q, H} \mathrm{E}[U(\tilde{\Pi})]
$$

subject to equation (1), where $E[\cdot]$ is the expectation operator with respect to the (subjective) joint probability distribution of $\tilde{P}_{1}, \tilde{P}_{2}, \ldots, \tilde{P}_{n}$.

\footnotetext{
${ }^{8}$ Throughout the paper, random variables have a tilde $(\sim)$ while their realizations do not.

${ }^{9}$ Location options embedded in a number of futures contracts can all be captured by the quality options of the type considered in this model.

${ }^{10}$ For simplicity, it is assumed that there are no delivery adjustments in the form of premiums and discounts. Otherwise, the model had to be based on the delivery-adjusted prices of grades 2 , $3, \ldots, n$.

${ }^{11}$ Production costs $C(Q)$ are compounded to $t=1$. Since transaction costs in the delivery process are neglected, there is no difference between cash settlement and physical delivery.
} 
The first-order conditions for an optimum are given by

$$
\begin{gathered}
\mathrm{E}\left[U^{\prime}\left(\tilde{\Pi}^{*}\right)\left(\tilde{P}_{1}-C^{\prime}\left(Q^{*}\right)\right)\right]=0, \\
\mathrm{E}\left[U^{\prime}\left(\tilde{\Pi}^{*}\right)\left(F-\min \left(\tilde{P}_{1}, \tilde{P}_{2}, \ldots, \tilde{P}_{n}\right)\right)\right]=0 .
\end{gathered}
$$

where an asterisk $\left(^{*}\right)$ indicates an optimal level. Given risk aversion and the convexity of the cost function, the second-order conditions for the unique maximum $\left(Q^{*}, H^{*}\right)$ are satisfied. The optimal output level is assumed to be positive, $Q^{*}>0$.

\section{Optimal production under delivery risk}

In this section, the firm's optimal production decision and its reaction to the introduction of delivery risk is examined. As a benchmark, we consider the hypothetical case in which only grade 1 of the commodity is deliverable. In this case, program (2) becomes

$$
\max _{Q_{a}, H_{a}} \mathrm{E}\left[U\left(\tilde{P}_{1} Q_{a}-C\left(Q_{a}\right)+\left(F_{a}-\tilde{P}_{1}\right) H_{a}\right)\right],
$$

where index $a$ indicates the absence of delivery options. In this case, the well-known separation and full-hedging theorems apply such that the firm's optimal output level $Q_{a}^{*}$ solves $C^{\prime}\left(Q_{a}^{*}\right)=F_{a}$ and the optimal futures position $H_{a}^{*}$ is a full hedge, $H_{a}^{*}=Q_{a}^{*}$, if the futures market is unbiased, $F_{a}=\mathrm{E}\left[\tilde{P}_{1}\right]^{12}$

Now, we return to the firm's decision problem in the presence of delivery risk. Equation (4) can be rewritten as

$$
\mathrm{E}\left[U^{\prime}\left(\tilde{\Pi}^{*}\right)\left(F-\tilde{P}_{1}-\min \left(0, \tilde{P}_{2}-\tilde{P}_{1}, \tilde{P}_{3}-\tilde{P}_{1}, \ldots, \tilde{P}_{n}-\tilde{P}_{1}\right)\right)\right]=0
$$

Substituting the above equation into equation (3) and rearranging terms yields

$$
C^{\prime}\left(Q^{*}\right)=F+V
$$

where $^{13}$

$$
V=\frac{\mathrm{E}\left[U^{\prime}\left(\tilde{\Pi}^{*}\right) \max \left(0, \tilde{P}_{1}-\tilde{P}_{2}, \tilde{P}_{1}-\tilde{P}_{3}, \ldots, \tilde{P}_{1}-\tilde{P}_{n}\right)\right]}{\mathrm{E}\left[U^{\prime}\left(\tilde{\Pi} \tilde{\Pi}^{*}\right)\right]}
$$

\footnotetext{
${ }^{12}$ See Holthausen (1979).

${ }^{13}$ Notice that $\min \left(0, P_{2}-P_{1}, P_{3}-P_{1}, \ldots, P_{n}-P_{1}\right)=-\max \left(0, P_{1}-P_{2}, P_{1}-P_{3}, \ldots, P_{1}-P_{n}\right)$.
} 
$V$ is positive since $U^{\prime}(\Pi)>0$ and $\max \left(0, P_{1}-P_{2}, P_{1}-P_{3}, \ldots, P_{1}-P_{n}\right) \geq 0$ with strict inequality in at least one state. ${ }^{14} \mathrm{~V}$ represents the firm's individual valuation of the payoff from the delivery option at $t=1$, calculated at $t=0$. Since marginal utility is evaluated at the optimum $\Pi^{*}$, this valuation generally depends upon the firm's optimal decisions due to wealth effects etc.

The difference between the futures price in the absence of a delivery option and the futures price in the presence of it, $\left(F_{a}-F\right)$, can be interpreted as the market's valuation of the delivery option. ${ }^{15}$ Of course, this difference is positive since it is the seller of the futures contract who has the right to exercise the option such that the futures price has to be reduced by the value of this option.

The reaction of the firm's optimal production decision to the introduction of delivery risk depends on the firm's individual valuation of the delivery option, $V$, relative to the value the market attaches to the delivery option as represented by $\left(F_{a}-F\right){ }^{16}$

It is important to notice that assuming different valuations is not a problem in futures markets since the existence of futures contracts requires at least some heterogeneity among futures market participants. Given this heterogeneity, it is likely that different (groups of) market participants attach different values to the futures contract and to the delivery option. ${ }^{17}$ Therefore, the value attached to the delivery option in a futures market equilibrium, $\left(F_{a}-F\right)$, generally differs from the

\footnotetext{
${ }^{14}$ If this condition is violated such that $\max \left(0, P_{1}-P_{2}, P_{1}-P_{3}, \ldots, P_{1}-P_{n}\right)=0$ in all states, grade 1 of the commodity is always the cheapest-to-deliver grade such that there is no delivery risk at all and, hence, $V=0$.

${ }^{15}$ It is not realistic to assume the coexistence of two futures contracts on the same commodity, one without delivery options, the other with such options. Hence, it would be somewhat misleading to call the difference $\left(F_{a}-F\right)$ a 'market value' in the usual sense since it is both impossible to observe this value as well as to trade the delivery option separately.

${ }^{16} \mathrm{It}$ is assumed that the distribution of the par-delivery grade's price $\tilde{P}_{1}$ is not affected by the existence of the delivery option in the futures contract.

${ }^{17}$ Since delivery options can be interpreted as options to exchange one grade for another, one can apply valuation models for exchange options such as that of Margrabe (1978) which is employed by Gay and Manaster (1984) for the valuation of the quality option in the case of two deliverable grades. A theoretical pricing model for any number of deliverable grades is presented by Boyle (1989). An overview on pricing is provided by Chance and Hemler (1993). Kamara (1990) demonstrates that the delivery structure has crucial implications for equilibrium pricing and, hence, market efficiency tests even if delivery uncertainty is relatively small.
} 
firm's subjective valuation, $V$.

Subtracting equation (5) from the condition $C^{\prime}\left(Q_{a}^{*}\right)=F_{a}$ results in $\left(F_{a}-F\right)-V=$ $C^{\prime}\left(Q_{a}^{*}\right)-C^{\prime}\left(Q^{*}\right)$. The convexity of the cost function directly implies the following proposition.

Proposition 1 If the risk-averse competitive firm attaches a higher value to the delivery option than the market does, $V>\left(F_{a}-F\right)$, introducing a delivery option induces the firm to raise its optimal level of production, $Q^{*}>Q_{a}^{*}$. If $V<$ $[=]\left(F_{a}-F\right)$, optimal production decreases [remains unchanged].

The intuition behind Proposition 1 is as follows: Notice first that the firm can always sell the marginal unit of its output via the futures market at the predetermined futures price which is either $F$ or $F_{a}$. In the absence of delivery risk, the firm optimally produces at the point where the marginal cost of production equals the deterministic marginal revenue $F_{a}$. In the presence of the delivery option, the firm receives the smaller futures price $F$. Taken in isolation, this decreases production since $\left(F_{a}-F\right)>0$. But by selling futures contracts, the firm also acquires the valuable delivery option. If profitable at maturity at $t=1$, the firm does not deliver its output of grade 1 , but sells this output at the spot price $P_{1}$ and uses part of the proceeds to purchase the cheapest-to-deliver grade at the spot price $\min \left(P_{2}, \ldots, P_{n}\right)$ in order to fulfill the futures contracts. It thereby generates an additional marginal revenue of $\max \left(0, P_{1}-P_{2}, P_{1}-P_{3}, \ldots, P_{1}-P_{n}\right)$. At $t=0$, this additional marginal revenue is stochastic but never negative (as is the case for any rational option exercise policy). The firm's individual valuation of this uncertain marginal revenue (in the optimum) is given by $V>0$. This additional marginal revenue increases production. In sum, the firm attaches a value of $(F+V)$ to its marginal revenue as indicated by equation (5).

The net effect of introducing a delivery option depends on the size of $V$ relative to $\left(F_{a}-F\right)>0$ which is the amount the firm has to pay for this option. If the increase in marginal revenue due to $V$ is higher than the decrease due to $\left(F_{a}-F\right)$, the 
optimal level of production is higher. If the reverse relation holds, optimal output is smaller. This is the statement of Proposition 1.

In addition, it follows directly from equation (5) and the definition of $V$ that the firm's optimal production decision depends on its assessment of the joint probability distribution of $\tilde{P}_{1}, \tilde{P}_{2}, \ldots, \tilde{P}_{n}$, and on its attitude towards risk. In other words, the separation theorem fails to hold when there is delivery risk. This is not surprising since there is no way to make the marginal revenue non-stochastic in the presence of non-tradable delivery risk.

\section{Optimal futures hedging under delivery risk}

In order to derive the optimal hedging position, it is necessary to impose some structure on the joint probability distribution of $\tilde{P}_{1}, \tilde{P}_{2}, \ldots, \tilde{P}_{n}$. For tractability, we shall consider two alternative specifications.

Assumption A The spot price of grade $i(i=2,3, \ldots, n)$ of the commodity at $t=1$ is related to that of grade 1 in the following additive manner:

$$
\tilde{P}_{i}=\tilde{P}_{1}+\tilde{\varepsilon}_{i}
$$

where $\tilde{\varepsilon}_{i}$ is a zero-mean random variable with support $\left[\underline{\varepsilon_{i}}, \overline{\varepsilon_{i}}\right]$. Apart from the assumption that $\underline{\varepsilon_{i}}+\underline{P_{1}}>0$ in order to guarantee $P_{i}>0$ in all states, $\tilde{\varepsilon}_{i}$ and $\tilde{P}_{1}$ are independent. ${ }^{18}$

Assumption $\mathbf{M}$ The spot price of grade $i(i=2,3, \ldots, n)$ of the commodity at $t=1$ is related to that of grade 1 in the following multiplicative manner:

$$
\tilde{P}_{i}=\left(1+\tilde{\gamma}_{i}\right) \tilde{P}_{1}
$$

where $\tilde{\gamma}_{i}$ is a zero-mean random variable with support $\left[\underline{\gamma_{i}}, \overline{\gamma_{i}}\right], 0<\underline{\gamma_{i}}<\overline{\gamma_{i}}<\infty$. $\tilde{\gamma}_{i}$ and $\tilde{P}_{1}$ are independent. ${ }^{19}$

As will be shown below, the firm's optimal futures position depends on which of these two assumptions holds. In order to focus on the hedging role of futures

\footnotetext{
${ }^{18}$ It is not necessary to assume that the $\tilde{\varepsilon}_{i}$ s are independent of each other.

${ }^{19}$ Again, the $\tilde{\gamma}_{i} \mathrm{~s}$ do not have to be independent of each other.
} 
contracts, it is assumed that the futures market is unbiased under either assumption A or assumption $\mathrm{M}$. That is, the futures price at $t=0$ equals the expected futures price at $t=1$ such that $F=\mathrm{E}\left[\min \left(\tilde{P}_{1}, \tilde{P}_{2}, \ldots, \tilde{P}_{n}\right)\right]$.

For the ease of exposition, we reformulate the firm's decision problem by fixing its output level at $Q^{*}$. Let $\mathrm{E} U=\mathrm{E}[U(\tilde{\Pi})]$, where $\tilde{\Pi}$ is defined in equation (1) with $Q=Q^{*}$. Partially differentiating $\mathrm{E} U$ with respect to $H$ yields

$$
\begin{aligned}
\frac{\partial \mathrm{E} U}{\partial H} & =\mathrm{E}\left[U^{\prime}(\tilde{\Pi})\left(F-\min \left(\tilde{P}_{1}, \tilde{P}_{2}, \ldots, \tilde{P}_{n}\right)\right)\right] \\
& =-\operatorname{cov}\left[U^{\prime}(\tilde{\Pi}), \min \left(\tilde{P}_{1}, \tilde{P}_{2}, \ldots, \tilde{P}_{n}\right)\right]
\end{aligned}
$$

where the second equality follows from the unbiasedness assumption. The right-hand side of equation (6) vanishes at $H=H^{*}$.

The following proposition characterizes the firm's optimal futures position under assumption A.

Proposition 2 Suppose that assumption A holds. If the futures market is unbiased, the firm's optimal futures position is a short under-hedge, $0<H^{*}<Q^{*}$.

Proof. Evaluating the right-hand side of equation (6) at $H=0$ and using assumption A results in

$$
\begin{aligned}
\left.\frac{\partial \mathrm{E} U}{\partial H}\right|_{H=0} & =-\operatorname{cov}\left[U^{\prime}\left(\tilde{P}_{1} Q^{*}-C\left(Q^{*}\right)\right), \tilde{P}_{1}+\min \left(0, \tilde{\varepsilon}_{2}, \tilde{\varepsilon}_{3}, \ldots, \tilde{\varepsilon}_{n}\right)\right] \\
& =-\operatorname{cov}\left[U^{\prime}\left(\tilde{P}_{1} Q^{*}-C\left(Q^{*}\right)\right), \tilde{P}_{1}\right]
\end{aligned}
$$

where the second equality follows from the fact that $\tilde{\varepsilon}_{i}$ is independent of $\tilde{P}_{1}$ for all $i=2,3, \ldots, n .^{20}$ Since $U^{\prime \prime}(\Pi)<0$, the right-hand side of equation (7) is positive. Thus, by the concavity of $\mathrm{E} U$, we have $H^{*}>0$.

Now, evaluating the right-hand side of equation (6) at $H=Q^{*}$ and using as-

\footnotetext{
${ }^{20}$ Two random variables $\tilde{X}$ and $\tilde{Y}$ are independent if and only if $\operatorname{cov}[F(\tilde{X}), G(\tilde{Y})]=0$ for all functions $F(\cdot)$ and $G(\cdot)$, see Ingersoll (1987).
} 
sumption A yields

$$
\begin{array}{r}
\left.\frac{\partial \mathrm{E} U}{\partial H}\right|_{H=Q^{*}}=-\operatorname{cov}\left[U^{\prime}\left(F Q^{*}-\min \left(0, \tilde{\varepsilon}_{2}, \tilde{\varepsilon}_{3}, \ldots, \tilde{\varepsilon}_{n}\right) Q^{*}-C\left(Q^{*}\right)\right),\right. \\
\left.\tilde{P}_{1}+\min \left(0, \tilde{\varepsilon}_{2}, \tilde{\varepsilon}_{3}, \ldots, \tilde{\varepsilon}_{n}\right)\right] \\
=-\operatorname{cov}\left[U^{\prime}\left(F Q^{*}-\min \left(0, \tilde{\varepsilon}_{2}, \tilde{\varepsilon}_{3}, \ldots, \tilde{\varepsilon}_{n}\right) Q^{*}-C\left(Q^{*}\right)\right),\right. \\
\left.\min \left(0, \tilde{\varepsilon}_{2}, \tilde{\varepsilon}_{3}, \ldots, \tilde{\varepsilon}_{n}\right)\right],
\end{array}
$$

where the second equality follows from the fact that $\tilde{\varepsilon}_{i}$ is independent of $\tilde{P}_{1}$ for all $i=2,3, \ldots, n$. Since $U^{\prime \prime}(\Pi)<0$, the right-hand side of equation (8) is negative. Thus, by the concavity of $\mathrm{E} U$, we have $H^{*}<Q^{*}$.

If the firm can use futures contracts to hedge against fluctuations in the spot price of its output at $t=1$, the unbiasedness of the futures market guarantees that this does not affect the firm's expected profits. Thus, any futures position taken by the firm only affects the firm's risk. Under assumption A, the futures contracts can be interpreted as a package of commodity price risk from $\tilde{P}_{1}$ and delivery risk from $\min \left(0, \tilde{\varepsilon}_{2}, \tilde{\varepsilon}_{3}, \ldots, \tilde{\varepsilon}_{n}\right)$. In particular, the additive combination of the two independent risks ensures that the amount of delivery risk embedded in each futures contract is invariant to different realizations of $\tilde{P}_{1} \cdot{ }^{21}$ As a result, hedging against commodity price risk arising from $\tilde{P}_{1}$ using futures contracts always generates the same exposure to delivery risk arising from $\min \left(0, \tilde{\varepsilon}_{2}, \tilde{\varepsilon}_{3}, \ldots, \tilde{\varepsilon}_{n}\right)$, thereby rendering a clear conflict between hedging against commodity price risk and creating delivery risk exposure. ${ }^{22}$ Complete elimination of commodity price risk calls for full hedging, $H=Q^{*}$, whereas complete elimination of delivery risk calls for no hedging, $H=0$. Since the two risks are independent, the firm cannot enter into a riskless position. Indeed, the firm's optimal futures position as stated in Proposition 2 is simply a compromise between full hedging and no hedging. The smaller the delivery risk relative to the commodity price risk, the more closely the optimal futures position approaches a full hedge.

\footnotetext{
${ }^{21}$ In a similar spirit, the cross hedging model of Benninga, Eldor and Zilcha $(1983,1984)$ is based on the assumption that basis risk is independent of the level of spot prices (regression approach).

${ }^{22}$ Alternatively put, the potential gain from exercising the delivery option is independent of $P_{1}$.
} 
Now, we turn to the firm's optimal futures position under assumption M.

Proposition 3 Suppose that assumption M holds. If the futures market is unbiased, the firm's optimal futures position is a short position, $H^{*}>0$.

Proof. Evaluating the right-hand side of equation (6) at $H=0$ and using assumption M, we have

$$
\begin{aligned}
& \left.\frac{\partial \mathrm{E} U}{\partial H}\right|_{H=0} \\
& =-\operatorname{cov}\left[U^{\prime}\left(\tilde{P}_{1} Q^{*}-C\left(Q^{*}\right)\right), \tilde{P}_{1}\left(1+\min \left(0, \tilde{\gamma}_{2}, \tilde{\gamma}_{3}, \ldots, \tilde{\gamma}_{n}\right)\right)\right] \\
& =-\operatorname{cov}\left[U^{\prime}\left(\tilde{P}_{1} Q^{*}-C\left(Q^{*}\right)\right)\left(1+\min \left(0, \tilde{\gamma}_{2}, \tilde{\gamma}_{3}, \ldots, \tilde{\gamma}_{n}\right)\right), \tilde{P}_{1}\right],
\end{aligned}
$$

where the second equality follows from the fact that $\tilde{\gamma}_{i}$ is independent of $\tilde{P}_{1}$ for all $i=2,3, \ldots, n .^{23}$ Since $U^{\prime \prime}(\Pi)<0$, the right-hand side of equation (9) is positive. Thus, by the concavity of $\mathrm{E} U$, we have $H^{*}>0$.

Under assumption $\mathrm{M}$, the conflict between hedging against commodity price risk and creating delivery risk is less clear-cut if contrasted to the conflict under assumption A. The multiplicative combination of $\tilde{P}_{1}$-risk and $\tilde{\gamma}$-risk from $\min \left(0, \tilde{\gamma}_{2}, \tilde{\gamma}_{3}, \ldots, \tilde{\gamma}_{n}\right)$ that characterizes assumption $\mathrm{M}$ implies that the amount of delivery risk embedded in each futures contract is higher the higher the realization of $\tilde{P}_{1}$. In other words, the potential benefit arising from the delivery option that is enjoyed by selling the futures contracts increases in $P_{1}$. It is this uncertainty about the trade-off between $\tilde{P}_{1}$-risk and $\tilde{\gamma}$-risk that is responsible for the lack of an unambiguous relationship between the optimal futures position and the optimal output level. Proposition 3 only states that the firm sells futures contracts, but it is completely silent about the optimality of under- or over-hedging.

However, one can derive a necessary and sufficient condition for the optimality of under- or over-hedging. At full hedging, $H=Q^{*}$, the firm's profits can be written as

\footnotetext{
${ }^{23}$ For any three random variables, $\tilde{X}, \tilde{Y}$, and $\tilde{Z}$, where $\tilde{X}$ and $\tilde{Y}$ are independent of $\tilde{Z}$, $\operatorname{cov}[\tilde{X}, \tilde{Y} \tilde{Z}]=\mathrm{E}[\tilde{X} \tilde{Y} \tilde{Z}]-\mathrm{E}[\tilde{X}] \mathrm{E}[\tilde{Y} \tilde{Z}]=\operatorname{cov}[\tilde{X} \tilde{Z}, \tilde{Y}]+\mathrm{E}[\tilde{X} \tilde{Z}] \mathrm{E}[\tilde{Y}]-\mathrm{E}[\tilde{X}] \mathrm{E}[\tilde{Y}] \mathrm{E}[\tilde{Z}]=\operatorname{cov}[\tilde{X} \tilde{Z}, \tilde{Y}]$ under mild regularity conditions.
} 
$\tilde{\Pi}=F Q^{*}-C\left(Q^{*}\right)-\min \left(0, \tilde{\gamma}_{2}, \gamma_{3}, \ldots, \tilde{\gamma}_{n}\right) Q^{*} \tilde{P}_{1}$. Due to the concavity of the problem, the optimal futures position $H^{*}$ is an under-hedge [full hedge] [over-hedge] if the right-hand side of equation (6) at $H=Q^{*}$ is negative [zero] [positive].

Evaluating the right-hand side of equation (6) at $H=Q^{*}$ under assumption M yields

$$
\begin{aligned}
&\left.\frac{\partial \mathrm{E} U}{\partial H}\right|_{H=Q^{*}}=-\operatorname{cov}\left[U^{\prime}\left(F Q^{*}-C\left(Q^{*}\right)-\min \left(0, \tilde{\gamma}_{2}, \gamma_{3}, \ldots, \tilde{\gamma}_{n}\right) Q^{*} \tilde{P}_{1}\right), \tilde{P}_{1}\right] \\
&-\operatorname{cov}\left[U^{\prime}\left(F Q^{*}-C\left(Q^{*}\right)-\min \left(0, \tilde{\gamma}_{2}, \gamma_{3} \ldots, \tilde{\gamma}_{n}\right) Q^{*} \tilde{P}_{1}\right),\right. \\
&\left.\tilde{P}_{1} \min \left(0, \tilde{\gamma}_{2}, \tilde{\gamma}_{3}, \ldots, \tilde{\gamma}_{n}\right)\right] .
\end{aligned}
$$

To sign the first covariance in (10), use the Law of Iterated Expectations to obtain

$$
\begin{aligned}
& \frac{\partial \mathrm{E}\left[U^{\prime}\left(F Q^{*}-C\left(Q^{*}\right)-\min \left(0, \tilde{\gamma}_{2}, \tilde{\gamma}_{3}, \ldots, \tilde{\gamma}_{n}\right) Q^{*} \tilde{P}_{1}\right) \mid P_{1}\right]}{\partial P_{1}} \\
& =-Q^{*} \mathrm{E}\left[U^{\prime \prime}(\cdot) \min \left(0, \tilde{\gamma}_{2}, \tilde{\gamma}_{3}, \ldots, \tilde{\gamma}_{n}\right) \mid P_{1}\right] .
\end{aligned}
$$

$\min \left(0, \tilde{\gamma}_{2}, \ldots, \tilde{\gamma}_{n}\right)$ is non-positive in all states and strictly negative in at least one state. Since $U^{\prime \prime}(\Pi)<0$ and $H=Q^{*}>0$, the expression in (11) and, hence, the first covariance in (10) is negative. For the same reason, the second covariance in (10) is positive. Thus, it is not possible to derive a general statement on whether the optimal futures position is an under- or an over-hedge. However, a necessary and sufficient condition for an under-hedge [over-hedge] is that the first covariance is smaller [larger] than the second covariance in absolute terms when evaluated at $H=Q^{*}$.

In the following numerical example, both under-hedging and over-hedging can be optimal under assumption $\mathrm{M}$ for different joint probability distributions of $\tilde{P}_{1}$ and the $\tilde{\gamma}_{i}$ s. The example is based on the following assumptions. There is only one alternative grade (say grade $x$ ) of the commodity whose spot price at $t=1$ is given by $\tilde{P}_{x}=\tilde{P}_{1}(1+\tilde{\gamma})$. In each scenario, the marginal probability distribution of $\tilde{P}_{1}$ has a three-point support: $P_{1}=50$ with probability $40 \%, P_{1}=50-\delta$ with probability $30 \%$ and $P_{1}=50+\delta$ with probability $30 \%$. Thus, $\tilde{P}_{1}$ is symmetrically distributed 
such that $\mathrm{E}\left[\tilde{P}_{1}\right]=50$ and $\operatorname{var}\left(\tilde{P}_{1}\right)=0.6 \delta^{2}$. The marginal probability distribution of $\tilde{\gamma}$ has a two-point support: $\gamma=-0.2$ and $\gamma=0.2$ with equal probability. In addition, $\mathrm{E}[\tilde{\gamma}]=0, \mathrm{E}[\min (0, \gamma)]=-0.1$, and $\operatorname{var}(\tilde{\gamma})=0.04$. There are six possible states in the joint probability distribution of $\tilde{P}_{1}$ and $\tilde{\gamma}$. Due to the independence of $\tilde{P}_{1}$ and $\tilde{\gamma}$, four of the states occur with probability $15 \%$ each, and the remaining two occur with probability $20 \%$ each. In all states, $P_{x}$ is either $20 \%$ higher or $20 \%$ lower than $P_{1}$. Hence, $\tilde{P}_{x}$ is not symmetrically distributed. These assumptions are summarized in Table 1. Furthermore, $F=\mathrm{E}\left[\tilde{P}_{1}\right](1+\mathrm{E}[\min (0, \tilde{\gamma})])=45$. The cost function is $C(Q)=0.025 Q^{2}$.

Table 1: The joint probability distribution

\begin{tabular}{|c|crcr|}
\hline state & probability & \multicolumn{1}{c}{$P_{1}$} & $\gamma$ & \multicolumn{1}{c|}{$P_{x}$} \\
\hline 1 & $15 \%$ & $50+\delta$ & +0.2 & $60+1.2 \delta$ \\
2 & $15 \%$ & $50+\delta$ & -0.2 & $40+0.8 \delta$ \\
3 & $20 \%$ & 50 & +0.2 & 60 \\
4 & $20 \%$ & 50 & -0.2 & 40 \\
5 & $15 \%$ & $50-\delta$ & +0.2 & $60-1.2 \delta$ \\
6 & $15 \%$ & $50-\delta$ & -0.2 & $40-0.8 \delta$ \\
\hline
\end{tabular}

Table 2 presents the optimal decisions for eleven scenarios that differ in the value of $\delta$, the spread parameter for $\tilde{P}_{1}$. For each scenario, the joint probability distribution is characterized by standard deviations and correlation coefficients. Then, the decisions are presented for a power utility function of $\hat{U}(\Pi)=-1 / \Pi$ such that relative risk aversion is equal to two and relative prudence is equal to three.

The first five columns of Table 2 exhibit the assumptions on $\delta$ and some characteristics of the joint probability distribution of $\tilde{P}_{1}$ and $\tilde{P}_{x}$. Column 1 gives the value of $\delta$. For example, $\delta=20$ means that $P_{1}$ is either 30,50 or 70 . Both the volatility of $\tilde{P}_{1}$ and $\tilde{P}_{x}$ increase in $\delta$ as columns 2 and 3 show. Columns 4 and 5 show the correlation coefficients $\rho(\cdot)$ for $\tilde{P}_{1}$ and $\tilde{P}_{x}$ and for $\tilde{P}_{1}$ and $\min \left(\tilde{P}_{1}, \tilde{P}_{x}\right)$. Both correlation coefficients are high, indicating that delivery risk is rather small in this example. 
Table 2: Optimal decisions for different levels of $\delta$

\begin{tabular}{|c|cccc|ccc|}
\hline \multicolumn{5}{|c|}{ joint distribution of $\tilde{P}_{1}$ and $\tilde{P}_{x}$} & \multicolumn{3}{c|}{ optimal decision for CRRA = } \\
\hline$\delta$ & $\operatorname{std}\left(\tilde{P}_{1}\right)$ & $\operatorname{std}\left(\tilde{P}_{x}\right)$ & $\rho\left(\tilde{P}_{1}, \tilde{P}_{x}\right)$ & $\rho\left(\tilde{P}_{1}, \min \left(\tilde{P}_{1}, \tilde{P}_{x}\right)\right)$ & $Q^{*}$ & $\left(H^{*}-Q^{*}\right)$ & $\left(H^{m v}-Q^{*}\right)$ \\
\hline 20 & 15.5 & 18.7 & 0.829 & 0.936 & 961.31 & -44.57 & -25.14 \\
21 & 16.3 & 19.4 & 0.840 & 0.941 & 960.82 & -36.86 & -15.22 \\
22 & 17.0 & 20.1 & 0.850 & 0.945 & 960.35 & -30.10 & -6.45 \\
23 & 17.8 & 20.7 & 0.859 & 0.949 & 959.89 & -24.14 & 1.32 \\
24 & 18.6 & 21.4 & 0.867 & 0.953 & 959.44 & -18.87 & 8.24 \\
25 & 19.4 & 22.1 & 0.875 & 0.956 & 959.00 & -14.17 & 14.42 \\
26 & 20.1 & 22.8 & 0.882 & 0.959 & 958.55 & -9.97 & 19.96 \\
27 & 20.9 & 23.6 & 0.888 & 0.961 & 958.10 & -6.21 & 24.95 \\
28 & 21.7 & 24.3 & 0.894 & 0.963 & 957.66 & -2.81 & 29.45 \\
29 & 22.5 & 25.0 & 0.899 & 0.965 & 957.20 & 0.27 & 33.53 \\
30 & 23.2 & 25.7 & 0.903 & 0.967 & 956.75 & 3.06 & 37.22 \\
\hline
\end{tabular}

The coefficients increase in $\delta$ because an increase in $\delta$ causes the covariances to grow at a higher rate than the products of the standard deviations. ${ }^{24}$

Columns 6 and 7 exhibit the optimal production and hedging decisions for constant relative risk aversion (CRRA) of two. Column 6 shows the optimal production decision. Optimal output slightly decreases in the volatility of the output price. ${ }^{25}$ This indicates that even significant changes in the volatility of tradable $\tilde{P}_{1}$-risk only have a minor impact on optimal output if there is delivery risk. ${ }^{26}$

Before analyzing the optimal futures position $H^{*}$ it is useful to consider the futures position that minimizes the variance of profits assuming that the firm has a given exposure of $Q^{*}$. This futures position, labeled $H^{m v}$, relative to the given exposure $Q^{*}$, is given in column $8 .^{27}$ Table 2 shows that the variance minimizing

\footnotetext{
${ }^{24}$ Due to the independence of $\tilde{P}_{1}$ and $\tilde{\gamma}$, we have $\operatorname{cov}\left(\tilde{P}_{1}, \tilde{P}_{x}\right)=\operatorname{var}\left(\tilde{P}_{1}\right)$.

${ }^{25}$ Therefore, the incorrectness made when presenting absolute differences in columns 7 and 8 instead of hedge ratios is negligible.

${ }^{26}$ In the absence of delivery risk, there is no impact at all because full hedging, $Q^{*}=H^{*}$, is optimal in an unbiased futures market.

${ }^{27} \mathrm{Of}$ course, the combination of $H^{m v}$ and $Q^{*}$ cannot be optimal if the firm is allowed to optimize over both $Q$ and $H$, because the optimal values of a firm that minimizes the variance of profits is $H=Q=0$.
} 
futures position monotonically increases in $\delta$. In particular, it is an under-hedging position for values of $\delta$ ranging from 20 to 22 , but turns into an over-hedging position for higher values of $\delta .^{28}$ In order to see why, notice that the variance of the firm's profit is given by

$$
\begin{aligned}
\operatorname{var}(\tilde{\Pi})= & (Q-H) \operatorname{var}\left(\tilde{P}_{1}\right)[(Q-H)-2 H \mathrm{E}[\min (0, \tilde{\gamma})]] \\
& +H^{2} \operatorname{var}\left(\tilde{P}_{1} \min (0, \tilde{\gamma})\right) .
\end{aligned}
$$

Hence, for given $Q$, the variance minimizing futures position $H^{m v}$ satisfies

$$
\begin{aligned}
& \left(Q-H^{m v}\right) \operatorname{var}\left(\tilde{P}_{1}\right)\{1+\mathrm{E}[\min (0, \tilde{\gamma})]\} \\
& -H^{m v}\left\{\operatorname{var}\left(\tilde{P}_{1} \min (0, \tilde{\gamma})\right)+\operatorname{var}\left(\tilde{P}_{1}\right) \mathrm{E}[\min (0, \tilde{\gamma})]\right\}=0 .
\end{aligned}
$$

The curly bracketed term in the first line of (12) is positive since $\underline{\gamma}>-1$. In the curly bracket sum in the second line, the first summand is positive while the second is negative. Due to this fact, the sum cannot be signed without making further assumptions on the marginal distributions of $\tilde{P}_{1}$ and $\tilde{\gamma}$. Obviously, full hedging at $H=Q$ is variance minimizing if and only if this sum is zero. Similarly, an underhedging position with $0<H<Q$ minimizes the variance of $\tilde{\Pi}$ if and only if the curly bracketed term in the second line in (12) is positive since the first line is positive in this case. Finally, an over-hedging position $H>Q>0$ is variance minimizing if and only if the sum in the second line is negative. ${ }^{29}$

Now, the optimal futures position $H^{*}$ as given in column 7 can be interpreted by comparing it to the variance minimizing position $H^{m v}$. $H^{*}$ is consistently smaller than $H^{m v}$; their difference increases in the variability of $\tilde{P}_{1}$. Suppose the firm starts from the variance minimizing futures position $H^{m v}$. Since the firm's preferences exhibit prudence, it does not only want to reduce the variability of its profit but it also wants to protect itself from very low realizations of profit (precautionary motive). The only way to satisfy the latter aim is to sell less futures than $H^{m v}$ for the following reason: The lowest realizations of profit occurs when the delivery

\footnotetext{
${ }^{28}$ At $\delta \approx 22.82$, full hedging is variance minimizing.

${ }^{29}$ For the case of two deliverable grades whose prices are jointly lognormally distributed with equal variance, Kamara and Siegel (1987) derive a related result where the variance minimizing hedge ratio may be above or below one.
} 
option expires worthless, that is when $P_{x}>P_{1}$ due to $\gamma>0$ and grade 1 is the cheapest to deliver. ${ }^{30}$ In these states, the firm's profit only depends on the realization of $\tilde{P}_{1}$. Generating additional profit for states with high $P_{1}$ requires selling less futures contracts. Starting from the variance minimizing position and taking the precautionary motive into account, it is optimal for a prudent firm to sell less futures contracts than $H^{m v} \cdot{ }^{31}$ Therefore, the optimal futures position is consistently smaller than the variance minimizing position. In relation to optimal output $Q^{*}$, the optimal futures position $H^{*}$ is an under-hedging position for values of $\delta$ between 20 and 28 . For larger values of $\delta$, over-hedging is optimal.

To sum up, a clear-cut statement on the optimal futures position relative to the firm's optimal output cannot be derived because the variance minimizing futures position under assumption $\mathrm{M}$ can be an over-hedging or an under-hedging position, depending on the marginal distributions of $\tilde{P}_{1}$ and $\tilde{\gamma}$. Preferences other than quadratic utility may lead to higher or smaller futures positions such that the difference $\left(H^{*}-Q^{*}\right)$ cannot be signed. In the example where preferences exhibit prudence, the optimal futures position is always below the variance minimizing position. In contrast, the variance minimizing position under the assumption $\mathrm{A}$ is always an under-hedging position. ${ }^{32}$ As Proposition 2 shows, this under-hedging position is preserved whatever the firm's preferences are.

\section{Conclusions}

Delivery options are a feature of nearly all commodity futures contracts. Quality options allow the seller to choose among several grades of the underlying commodity. Due to the quality option, the futures price on the delivery day does not converge to the spot price of the par-delivery grade but to the spot price of the cheapest-to-

\footnotetext{
${ }^{30}$ Of course, this holds for $H>0$ only because the delivery option can be exercised by the seller of a futures contract. However, Proposition 3 states that $H^{*}$ is always positive under assumption M.

${ }^{31}$ Under quadratic utility, the optimal and the variance minimizing futures position coincide in an unbiased futures market.

${ }^{32}$ This can be easily seen from the condition for the variance minimizing futures position under assumption $A$ which is $\left(H^{m v}-Q\right) \operatorname{var}\left(\tilde{P}_{1}\right)+H^{m v} \operatorname{var}\left(\min \left(0, \tilde{\varepsilon}_{2}, \tilde{\varepsilon}_{3}, \ldots, \tilde{\varepsilon}_{n}\right)\right)=0$.
} 
deliver grade of the commodity. Hence, any futures position carries an additional delivery risk in addition to commodity price risk. Hedgers seeking to manage their commodity price risk are faced with this untradable delivery risk.

This paper examined the optimal production and futures hedging decisions for a risk-averse competitive firm in the presence of delivery risk arising from a quality option. The three main results can be summarized as follows: First, if the firm attaches a higher value to the delivery option than the market does, the existence of the delivery option induces the firm to produce more than in the absence of a delivery option. The second and third result relate to optimal risk management. If the delivery risk is additively related to commodity price risk, the firm will always under-hedge the exposure created by its production decision. This result changes significantly if the delivery risk is multiplicatively related to commodity price risk such that the deviations between the par-grade and the cheapest-to-deliver grade increase in the level of the par-grade spot price at delivery. In this case, the firm's optimal futures position may also be an over-hedge of its exposure. The reason for the optimality of over-hedging in the presence of untradable delivery risk is the fact that under this specification, the variance minimizing futures position is not necessary a full hedge but may itself be an over-hedge. A numerical example shows how the variance minimizing hedge ratio and the hedge ratio optimal for constant relative risk aversion vary with the amount of delivery risk relative to the price risk associated with a futures contract.

\section{References}

Benninga, S., Eldor, R., \& Zilcha, I. (1983). Optimal hedging in the futures market under price uncertainty. Economics Letters, 13, 141-145.

Benninga, S., Eldor, R., \& Zilcha, I. (1984). The optimal hedge ratio in unbiased futures markets. Journal of Futures Markets, 4, 155-159.

Boyle, Ph.P. (1989). The quality option and timing option in futures contracts. Journal of Finance, $44,101-113$.

Chance, D.M., \& Hemler, M.L. (1993). The impact of delivery options on futures prices: A survey. Journal of Futures Markets, 13, 127-155.

Garbade, K.D., \& Silber, W.L. (1983a). Futures contracts on commodities with multiple varieties: An analysis of premiums and discounts. Journal of Business, 56, 249-272. 
Garbade, K.D., \& Silber, W.L. (1983b). Cash settlement of futures contracts: An economic analysis. Journal of Futures Markets, 3, 451-472.

Gay, G.D., \& Manaster, S. (1984). The quality option implicit in futures contracts. Journal of Financial Economics, 13, 353-370.

Gay, G.D., \& Manaster, S. (1986). Implicit delivery options and optimal delivery strategies for financial futures contracts. Journal of Financial Economics, 16, 41-72.

Gay, G.D., \& Manaster, S. (1991). Equilibrium treasury bond futures pricing in the presence of implicit delivery options. Journal of Futures Markets, 11, 623-645.

Hemler, M.L. (1990). The quality delivery option in treasury bond futures contracts. Journal of Finance, 45, 1565-1586.

Holthausen, D.M. (1979). Hedging and the competitive firm under price uncertainty. American Economic Review, 69, 989-995.

Ingersoll, J.E. (1987). Theory of financial decision making. Totowa: Rowman and Littlefield.

Kamara, A. (1990). Delivery uncertainty and the efficiency of futures markets. Journal of Financial and Quantitative Analysis, 25, 45-64.

Kamara, A., \& Siegel, A. (1987). Optimal hedging in futures markets with multiple delivery specifications. Journal of Finance, 42, 1007-1021.

Kane, A., \& Marcus, A.J. (1986). Valuation and optimal exercise of wild card option in the Treasury bond futures market. Journal of Finance, 41, 195-207.

Lence, S.H. (1995). On the optimal hedge under unbiased futures prices. Economics Letters, 47, $385-388$.

Lien, D. (1988). Hedger response to multiple grades of delivery on futures markets. Journal of Futures Markets, 8, 687-702.

Lien, D. (1991). Long hedgers and multiple delivery specifications on futures contracts. Journal of Futures Markets, 11, 557-565.

Lien, D., \& Wong, K.P. (2002). Delivery risk and the hedging role of options. Journal of Futures Markets, 22, 339-354.

Margrabe, W. (1978). The value of an option to exchange one asset for another. Journal of Finance, 33, 177-186.

Peck, A.E., \& Williams, J.C. (1991). Deliveries on Chicago Board of Trade: Wheat, corn, and soybean futures contracts, 1964/65-1988/89. Food Research Institute Studies, 22, 129-225.

Peck, A.E., \& Williams, J.C. (1992). Deliveries on commodity futures contracts. Economic Record, Supplement: Special Issues on Futures Markets, 63-74.

Pirrong, S.C. (1993). Manipulation of the commodity futures market delivery process. Journal of Business, 66, 335-369.

Pirrong, C. (2001). Manipulation of cash-settled futures contracts. Journal of Business, 74, 221244.

Pirrong, S.C., Kormendi, R., \& Meguire, Ph. (1994). Multiple delivery points, pricing dynamics, and hedging effectiveness in futures markets for spatial commodities. Journal of Futures Markets, 14, 545-573.

Viswanath, P.V., \& Chatterjee, S. (1992). Robustness results for regression hedge ratios: Futures contracts with multiple deliverable grades. Journal of Futures Markets, 12, 253-263. 